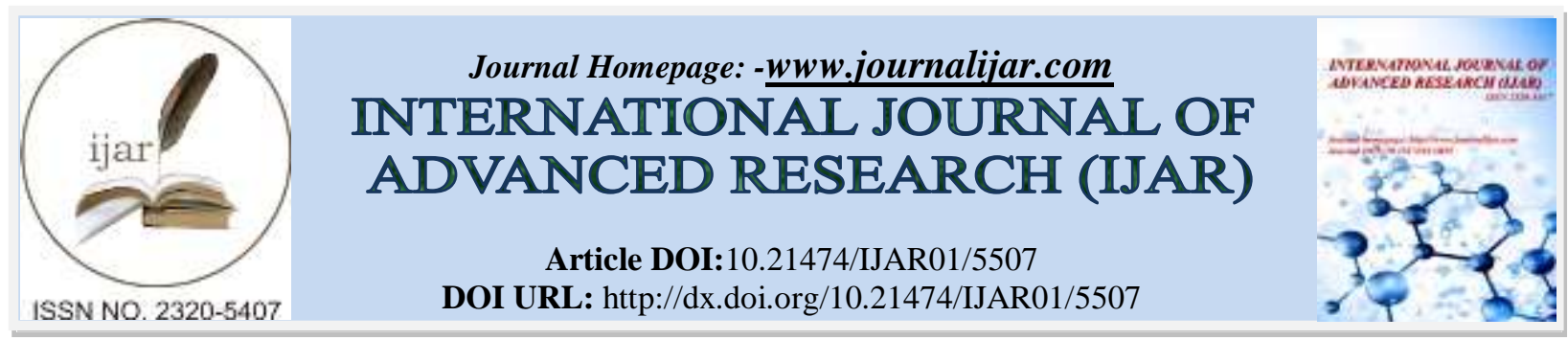

RESEARCH ARTICLE

\title{
EFFECTS OF THE FREE MATERNITY CARE PROGRAM ON CLIENT SATISFACTION AT A COUNTY REFERRAL HOSPITAL IN KENYA.
}

1. $\mathrm{MScN}(\mathrm{MNH}), \mathrm{BScN}, \mathrm{KRCHN}$.

\section{Mukabana Beatrice $^{1}$ and Victor Emali Mukaka ${ }^{2}$.}

2. MPH(Epidemiology and Research Methods), BScN, KRCHN.

\section{Manuscript Info}

Manuscript History

Received: 01 August 2017

Final Accepted: 03 September 2017

Published: October 2017

\begin{abstract}
Maternal mortality is a serious problem particularly in resource strained countries including Kenya. Many countries have come up with various reproductive health interventions with the aim of reducing the maternal mortality. In Kenya, one such key intervention was the introduction of the Free Maternity care program whose objective was to increase access and improve utilization of maternity services with the aim of reducing maternal mortality. This study aimed at establishing the effects of Free Maternity Care program (FMC) on the level of client satisfaction on quality of care in the era of free maternity care program at Kakamega County Referral Hospital. It was a Hospital based crosssectional descriptive design involving 223 post natal mothers selected systematically. Questionnaire and interview schedule were the main data collection tools. Independent t-test and chi-square were used in analysis which was done by use of SPSS V. 20. P-value less than 0.05 was considered significant. Qualitative data was analyzed thematically. Majority of the clients interviewed were satisfied with the services offered. Higher proportion of those with lower education level were satisfied compared to those with higher levels of education $(77.1 \%$ vs. $56.3 \%, \chi 2=10.841, \mathrm{p}=0.001)$. In conclusion, the administrators, health care providers and the clients all agreed that the program was satisfactory despite some challenges which needed to be addressed by the policy makers. Efforts should therefore be made to sustain the Free Maternity Care program including the policy makers addressing the challenges.
\end{abstract}

Copy Right, IJAR, 2017,. All rights reserved.

\section{Introduction:-}

According to Dzakpasu et al. (2012), many factors can influence the rate at which women seek skilled birth attendance services including the cost of care. This has led to a growing movement, globally and particularly in the Africa region, to reduce financial barriers to health care generally, but with special emphasis on high priority services and vulnerable groups. This aims at increasing utilization of health care services and thus reducing maternal mortality. A long list of countries including Benin, Burkina Faso, Burundi, Cameroon, Ethiopia, Ghana, Kenya, Liberia, South Africa, Nepal, Mali, Senegal, Zambia, Uganda, Niger, and Sudan have pursued fee removal or exemption policies for delivery care and/or caesarean section as revealed by (McPake et al., 2013) He also support the fact that if the Free Health care policies work as intended, service utilization rates increase. 
The most recent estimates by the Kenya Demographic Health Survey (2014) set the maternal mortality rate in Kenya at 362 deaths per 100,000 live births, well above the MDG target of 147 per 100,000 by 2015. Despite improvement in other health indicators, the high rates have persisted. The problem is driven partly by lack of access to quality maternal health care services, including ante-natal, childbirth, and post-natal services. KDHS (2010) report indicate that although more than 90 percent of Kenyan women received antenatal care from a medical professional, fewer than half of all births took place in a health facility. In 2007, the country developed the National Reproductive Health Policy Framework whose goal was to improve reproductive health state of all people in Kenya by increasing equitable access and improving quality, efficiency and effectiveness of service delivery at all levels and improving responsiveness to clients' needs. The main objective was to establish the level of client satisfaction on quality of care in the era of free maternity care program.

\section{Materials and Methods:-}

The study was hospital based cross-sectional conducted at Kakamega County Referral Hospital which is situated in Kakamega town. One health care provider from each department was sampled (maternity unit-labor ward, postnatal ward and antenatal ward, maternity theater, laboratory, radiology department, $\mathrm{MCH}$ and pharmacy). Permission was sought from the Kakamega County hospital Ethics and Research Committee after the study had been approved by IREC Moi University. Research assistants had a two days training on the data collection procedure. Data collection was then done from $22^{\text {nd }}$ April 2015 to $21^{\text {st }}$ May 2015. Data was collected using a questionnaire and an interview schedule.

\section{Statistical analysis:-}

Questionnaires were coded and entered into Epidata V 3.1 computer software. It was later transferred to SPSS V.20 for analysis. Descriptive statistics (frequencies, means and standard deviation) were used to summarize the data. To compare satisfaction levels, independent samples t-test was used for continuous/discrete variables while Chi-square was used for categorical variables. P-value $<0.05$ was considered significant. Results are presented in form of tables, bar-graphs and pie-charts. Qualitative data from the health care providers, administrators were analyzed in themes as they emerged.

\section{Findings:-}

A total of 223 clients were interviewed. Their mean age (in years) was 25.1(SD 7.6). The median parity (IQR) was $3(1,4)$. Most of them were married $139(62.3 \%)$ and a significant number $119(54.1 \%)$ was unemployed. A majority of the respondents $113(51.6 \%)$ had primary level education and most of them 146(65.5\%) were Christians.

Table1:- Socio-demographic characteristics.

\begin{tabular}{|l|l|}
\hline Characteristic & Frequency (\%) \\
\hline Marital status & \\
Single & $67(30)$ \\
Married & $139(62.3)$ \\
Widowed & $8(3.6)$ \\
Separated & $9(4.1)$ \\
\hline Occupation & \\
Employed & $25(11.4)$ \\
Unemployed & $119(54.1)$ \\
Self employed & $41(18.6)$ \\
Student & $35(15.9)$ \\
\hline Education & \\
None & $7(3.2)$ \\
Primary & $113(51.6)$ \\
Secondary & $71(32.4)$ \\
Tertiary & $28(12.8)$ \\
\hline Religion & \\
Christian & $146(65.5)$ \\
Muslim & $75(33.6)$ \\
Others & $2(0.9)$ \\
\hline
\end{tabular}




\section{Length of stay in the ward:-}

Majority $170(76.9 \%)$ had stayed in the ward for days and only 4(1.8\%) had stayed for months (fig.1)

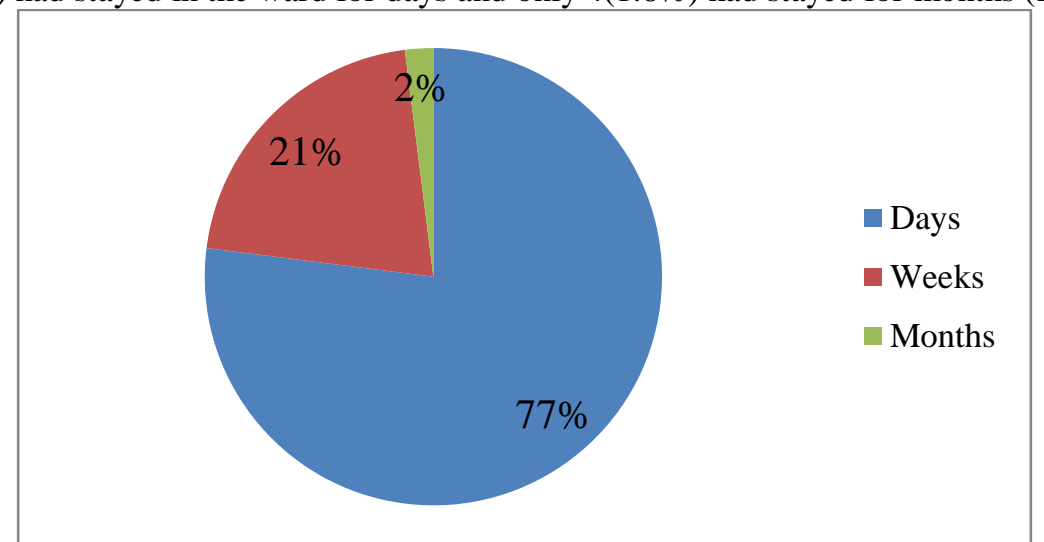

Fig 1:- Length of stay in the ward

More than half of the patients $129(57.8 \%)$ had been admitted to the ward before the free maternity care program and only 58(26\%) were satisfied. Among the satisfied, majority 36(62\%) reported friendly staff while $15(25.9 \%)$ reported that it was because of good environment (Fig.2).

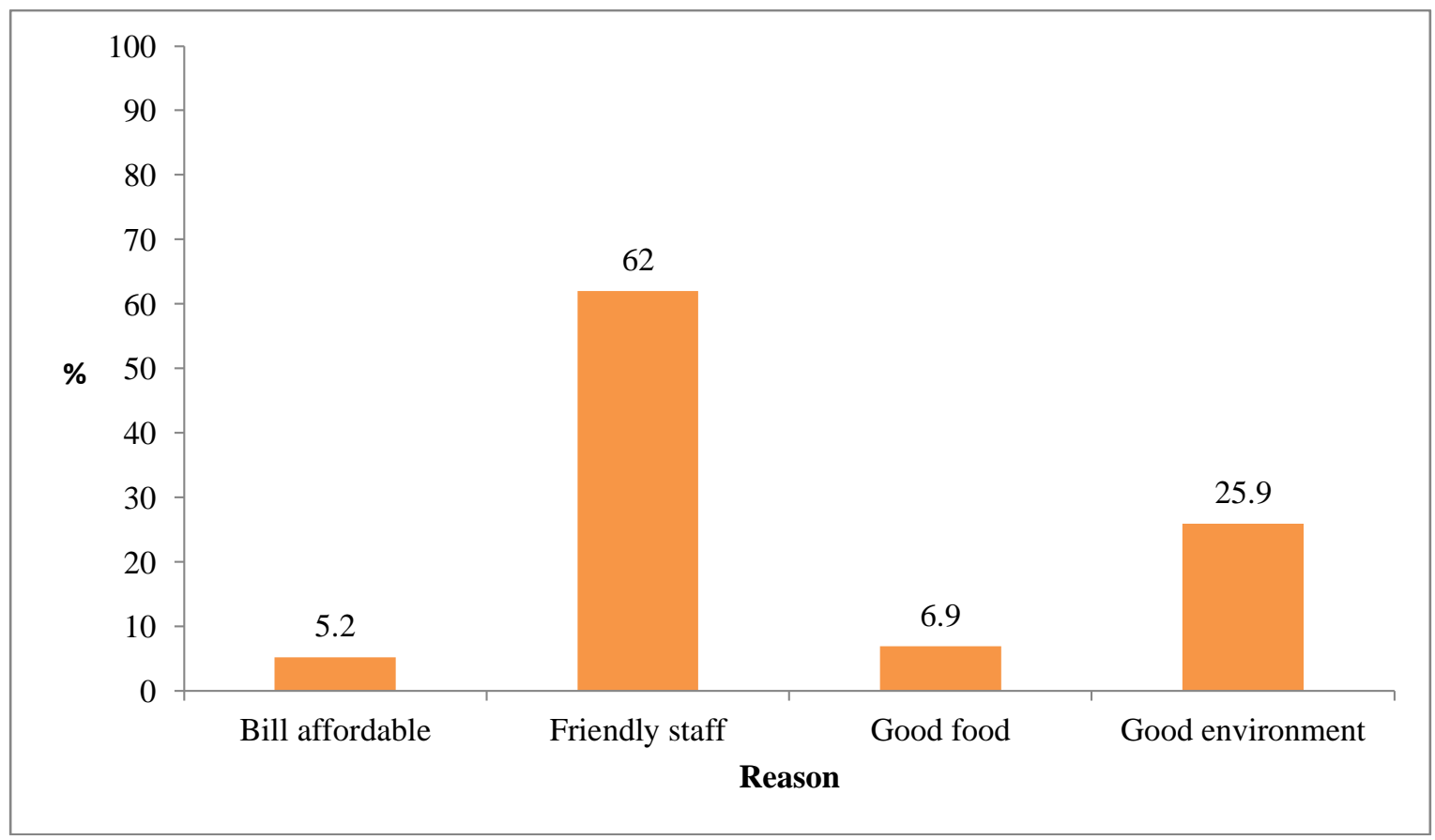

Fig 2:- Reason for satisfaction 
Among the dissatisfied, 51(72.9\%) was because of high bill, 11(15.7\%) unfriendly staff (fig. 3)

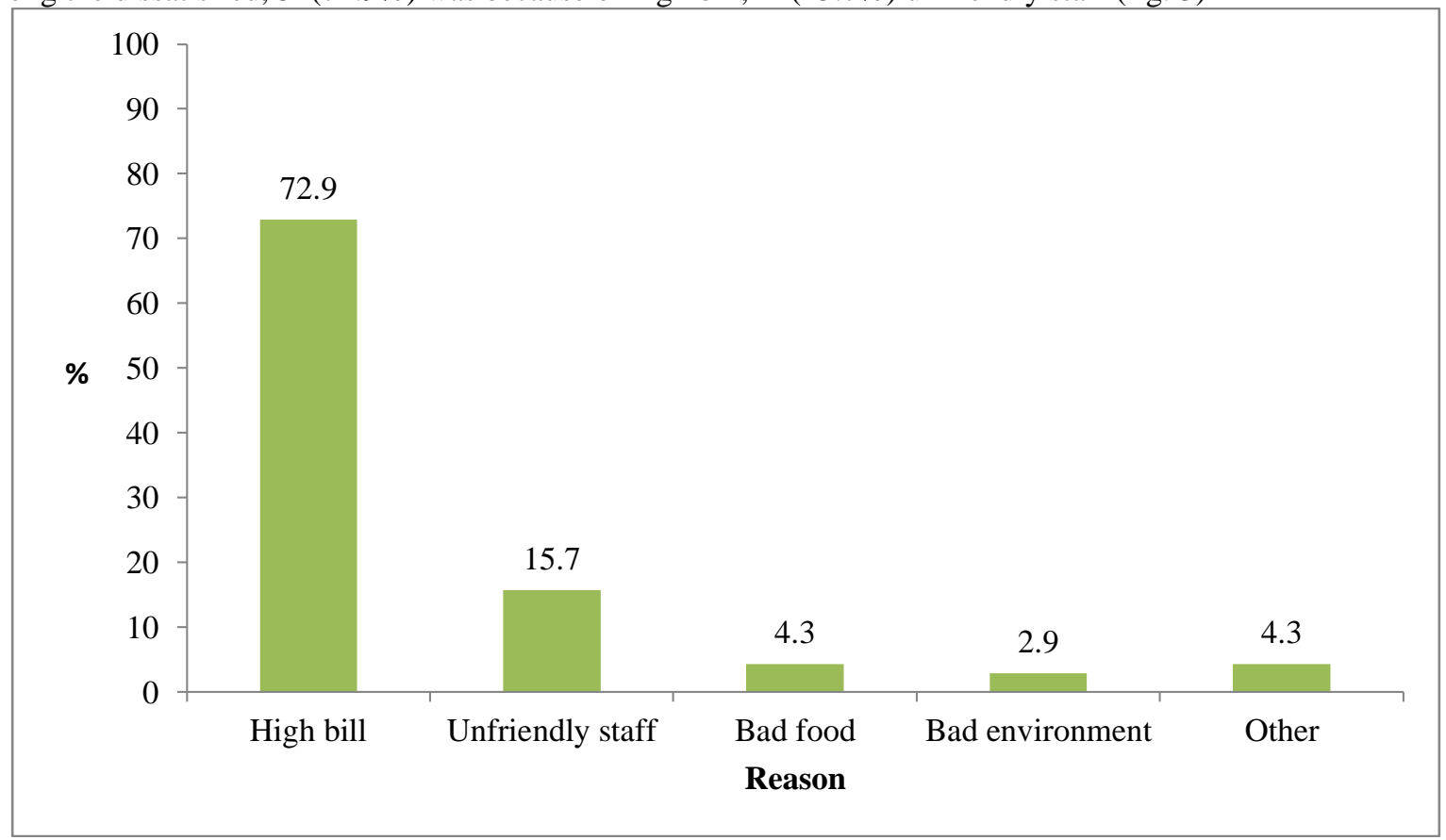

Fig 3:- Reason for dissatisfaction

Majority rated the services received as good $135(61.7 \%)$ and only a small number 3(1.4\%) rated it as poor (fig 4)

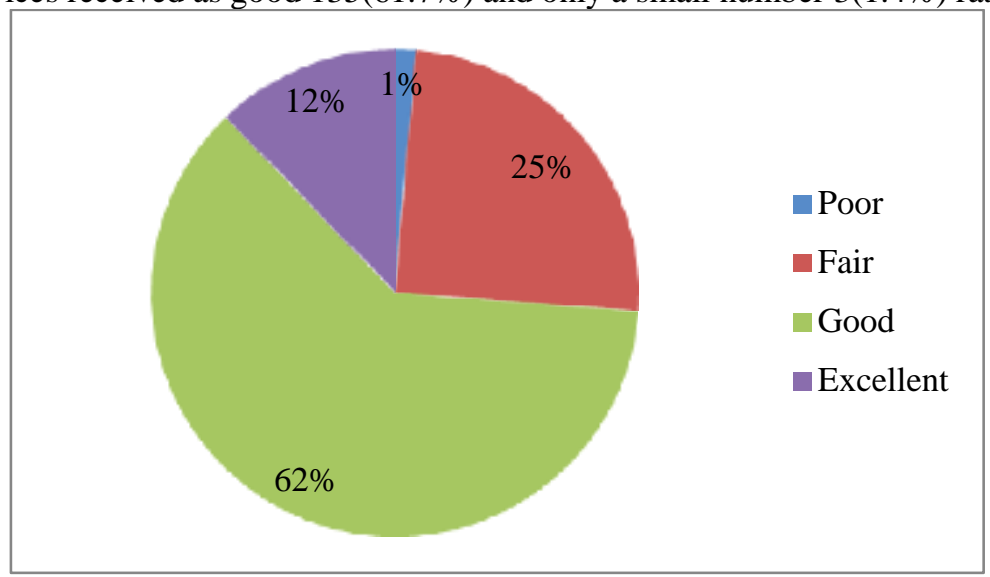

Fig 4:- Quality of service

Close to half $106(47.7 \%)$ received quality services they wanted and 65(29.3\%) did not (table 2 )

Table 2:- Received quality service wanted

\begin{tabular}{|l|l|}
\hline Response & Frequency (\%) \\
\hline No definitely & $15(6.8)$ \\
\hline No not really & $50(22.5)$ \\
\hline Yes, generally & $51(23)$ \\
\hline Yes, definitely & $106(47.7)$ \\
\hline
\end{tabular}

More than half $137(61.7 \%)$ of the respondents would definitely recommend the facility to other clients and only $16(7.3 \%)$ would not do so (table 3 ) 
Table3:- Recommend the facility to other clients

\begin{tabular}{|l|l|}
\hline Recommend & Frequency $(\%)$ \\
\hline No definitely & $3(1.4)$ \\
\hline No don't think & $13(5.9)$ \\
\hline Yes, think so & $69(31.1)$ \\
\hline Yes, definitely & $137(61.7)$ \\
\hline
\end{tabular}

Majority of the patients $197(88.7 \%)$ were willing to come back to the facility and only $25(11.3 \%$ ) were not (fig 5)

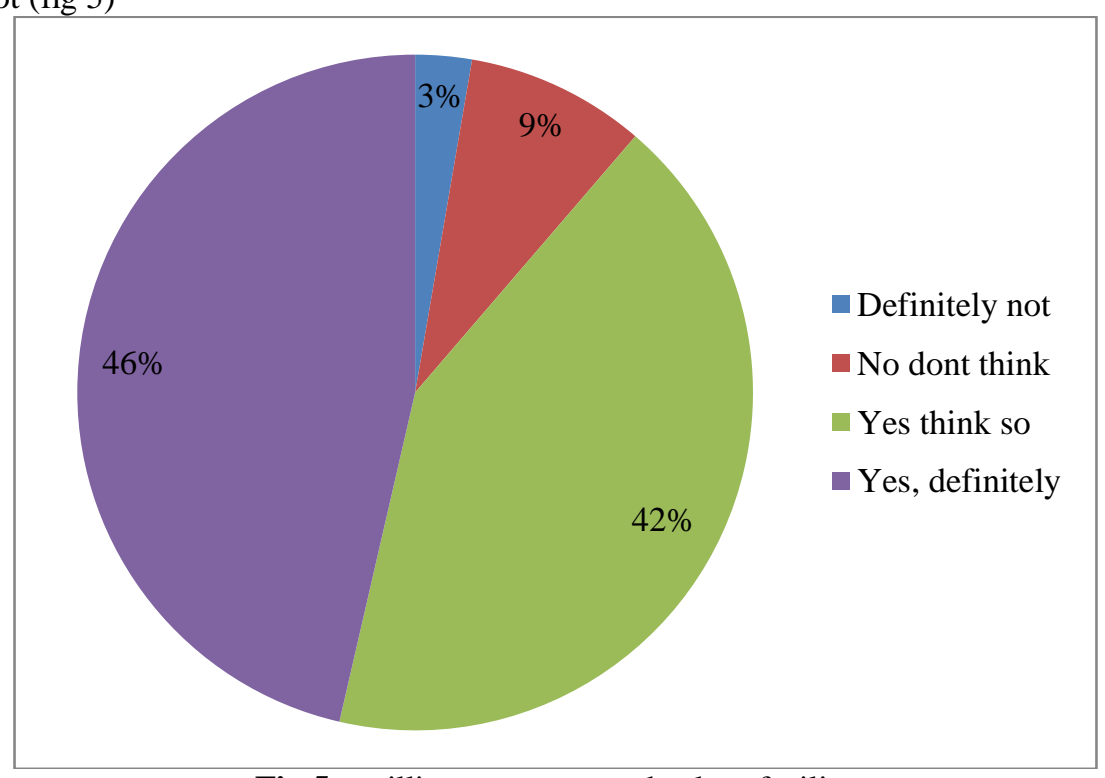

Fig 5:- willingness to come back to facility

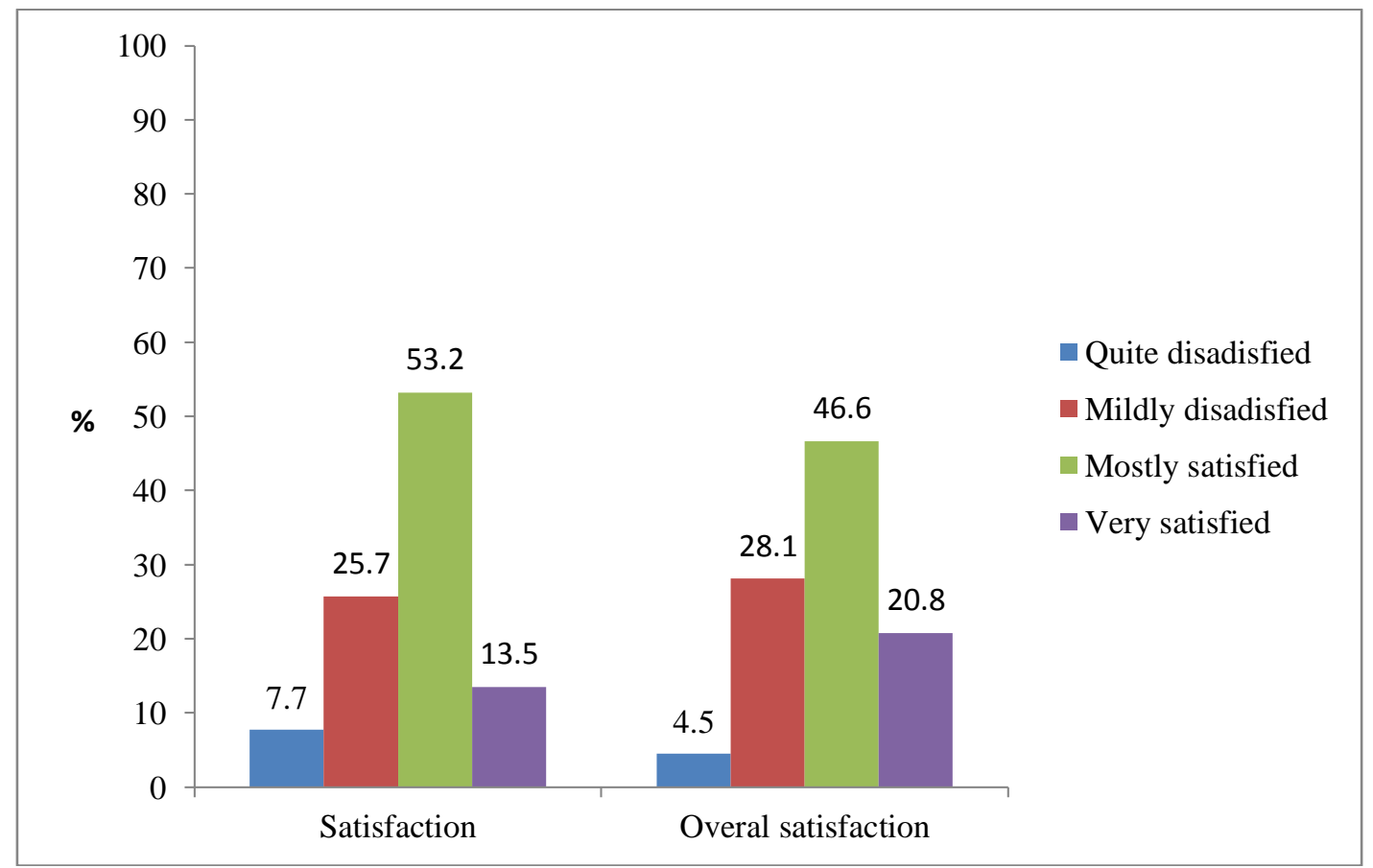

Fig 6:- Satisfaction with services 
As in figure 6, overall only $72(32.6 \%$ ) of the clients were dissatisfied with the facility services while more than half of the clients 151(67.4) were satisfied

Table 4:- Factors associated with client satisfaction

\begin{tabular}{|c|c|c|c|c|}
\hline Factor & \multicolumn{2}{|c|}{ Satisfaction } & \multirow[t]{2}{*}{ statistic } & \multirow[t]{2}{*}{ p-value } \\
\hline & Satisfied & Dissatisfied & & \\
\hline Age & $25.6 \pm 7.9$ & $24.2 \pm 7.1$ & $\mathrm{t}=1.303$ & 0.194 \\
\hline Parity & $2.5 \pm 3.9$ & $2.3 \pm 3.9$ & $\mathrm{t}=1.128$ & 0.260 \\
\hline $\begin{array}{l}\text { Marital status } \\
\text { Single } \\
\text { Married } \\
\text { Other }\end{array}$ & $\begin{array}{l}23(34.3) \\
43(31.4) \\
6(35.3)\end{array}$ & $\begin{array}{l}44(65.7) \\
94(68.6) \\
11(64.7)\end{array}$ & $\chi^{2}=0.239$ & 0.887 \\
\hline $\begin{array}{l}\text { Occupation } \\
\text { Employed } \\
\text { Unemployed } \\
\text { Self employed } \\
\text { Student }\end{array}$ & $\begin{array}{l}8(32) \\
34(28.6) \\
14(35.9) \\
16(45.7)\end{array}$ & $\begin{array}{l}17(68) \\
85(71.4) \\
25(64.1) \\
19(54.3)\end{array}$ & $\chi^{2}=3.772$ & 0.287 \\
\hline $\begin{array}{l}\text { Education } \\
\leq \text { Primary } \\
\geq \text { Secondary }\end{array}$ & $\begin{array}{l}27(22.9) \\
45(43.7)\end{array}$ & $\begin{array}{l}91(77.1) \\
58(56.3)\end{array}$ & $\chi^{2}=10.841$ & $0.001^{*}$ \\
\hline $\begin{array}{l}\text { Religion } \\
\text { Christian } \\
\text { Muslim } \\
\end{array}$ & $\begin{array}{l}41(28.5) \\
31(40.3)\end{array}$ & $\begin{array}{l}103(71.5) \\
46(59.7)\end{array}$ & $\chi^{2}=3.174$ & 0.075 \\
\hline $\begin{array}{l}\text { Length of stay in war } \\
\text { Days } \\
\text { Weeks } \\
\text { Months }\end{array}$ & $\begin{array}{l}60(35.7) \\
11(23.4) \\
1(25)\end{array}$ & $\begin{array}{l}108(64.3) \\
36(76.6) \\
3(75)\end{array}$ & $\chi^{2}=2.636$ & 0.268 \\
\hline $\begin{array}{l}\text { Ever admitted before } \\
\text { Yes } \\
\text { No }\end{array}$ & $\begin{array}{l}42(33.1) \\
30(32.3)\end{array}$ & $\begin{array}{l}85(66.9) \\
63(67.7)\end{array}$ & $\chi 2=0.016$ & $1.000^{*}$ \\
\hline
\end{tabular}

Among the factors associated with client satisfaction, only education was found to be significant $(\chi 2=10.841$, $\mathrm{p}=0.001)$. Higher proportion of those with lower education level were satisfied compared to those with higher levels of education $(77.1 \%$ vs. $56.3 \%)$

On the level of client satisfaction in the era of FMC program as a theme, they all thought that it was very low. They reported that the clients were not satisfied because the services were poor, they shared beds and the environment was dirty because of the congestion. A staff in pharmacy said that the clients went as far as quarreling them especially when they are told that the drugs are out of stock.

In postnatal ward a health care provider commented "what do you mean level of client satisfaction? Can you be satisfied in such an environment? Congested and even sharing the bed and the linen....they are not satisfied at all."

The key objective of the study was to establish the level of client satisfaction on quality of care in the era of free maternity care policy. A total of 223 clients were interviewed. Their mean age (in years) was 25.1(SD 7.6). A majority of the respondents $113(51.6 \%)$ had primary level education and most of them 146(65.5\%) were Christians. More than half of the patients $129(57.8 \%)$ had been admitted to the ward before the FMC and only 58(26\%) were satisfied. Among the satisfied, majority $36(62 \%)$ reported friendly staff while $15(25.9 \%)$ reported that it was because of good environment.

\section{Discussion:-}

Mean age in years in this study is similar to that of KDHS (2014) and this could probably be because fertility rate of women picks broadly around this age. It is for this reason that most of the women in the postnatal ward were around this age. These results are also similar to results from other studies which established that determinant of client satisfaction included friendliness from the health care providers and clean and comfortable environment (Nyongesa 
et al., 2014; Schoenfelder et al., 2011; Chawani, 2009). When the environment is clean, one feels comfortable and will want to come back to the same place for services and the relationship created between the client and the health care provider will also make the client either to be satisfied or to be dissatisfied.

More than half would definitely recommend the facility to other clients and majority of the clients were willing to come back to the facility. According to Bazant and Koenig (2009), recommending the facility to other clients and the willingness to come back to the same facility for care indicates that the client was satisfied with services she received. These results are in line with results of the study carried out in Nairobi's informal settlements on women's satisfaction with delivery care. The results are ascribed to the fact that the environment was clean making the clients to feel comfortable and the health care providers were friendly.

Close to half of the respondents reported to have received quality services that they wanted. Many studies indicate that quality of care is a measure of client satisfaction but they also agree that definition of quality is an individual's perspective and therefore subjective. A Meta Synthesis on patient satisfaction with nursing care carried out by Chawani (2009) revealed 49 themes related to client satisfaction. The themes were ranked according to their importance and quality of care was ranked second to caring. This therefore implies that the respondents in this study were satisfied with the services they received.

Furthermore overall, more than half of the clients (67.4\%) were satisfied with the services offered. This percentage though is slightly lower than that noted by a comprehensive assessment report (2015) carried out by the Ministry of health in Kenya which indicated that $80 \%$ of the clients were satisfied with the services offered and the interpersonal skills of the heath care staffs. The difference in percentage could be due to the fact that in the comprehensive report, many parameters to define quality were measured compared to only few that were measured in this study and the sample size was also big.

Among the factors associated with client satisfaction, only education was found to be significant as higher proportion of those with lower education level was satisfied compared to those with higher levels of education. These results are similar to those of a Meta Synthesis analysis by (Chawani, 2009). In the Meta Synthesis, it was noted that the educational levels of patient can influence patients' expectations of nursing care and satisfaction. It reported that educational levels of the patient influence the patients' expectations of care where patients with high levels of education were reported to be dissatisfied with the quality of care provided. One of the reasons could be that patients with high levels of education demand more information on quality of care and always try to establish trusting nurse-patient relationships. The same analysis reported that greater satisfaction is associated with less education. It may be concluded that patients with less education do not know what they are entitled to or what constitutes good quality care. A study in Ghana on determinants of Consumer Satisfaction of Health Care also had the same results (Nketiah-Amponsah, 2009). Most of the clients who utilized the services in the post FMC program period had attained primary level education and this explains why the level of client satisfaction was high.

Majority of the clients had heard of the FMC and they understood the services that were being offered under the policy unlike the respondents in the study carried out by Adei et al. (2012) which revealed that although the women had heard about free maternal health care under the NHIS scheme, they did not know what it entailed. However some of them were not sure of the services offered under the program. There is therefore need to reinforce on the scope of FMC program.

\section{Conclusion and recommendations:-}

\section{Conclusion:-}

Majority of the clients interviewed were satisfied with the services offered. Education was found to be a significant predictor of client satisfaction. The administrators, health care providers and the clients all agreed that the program was satisfactory despite some challenges which needed to be addressed by the policy makers.

\section{Recommendation:-}

1. National and County governments need to put strategies which will help them to jointly assess, map and plan investments to improve quality of service delivery for FMC through prioritizing investments in Human Resource, infrastructure and commodities based on the anticipated demand for FMC.

2. Since some of the mothers were not sure of the services offered under the program, there is therefore need to reinforce on the scope of FMC program 
3. Though the program was satisfactory, efforts should be made to sustain the Free Maternity Care program including the policy makers addressing the challenges associated with the program

\section{References:-}

1. Adei, D., Fiscian, Y., Ephraim, L., and Diko S. (2012). Access to Maternal Health Care Services in the Cape Coast Metropolitan Area, Ghana. Current Research Journal of Social Sciences 4(1): 12-20, 2012 ISSN: 20413246

2. Bazant, E. S., \& Koenig, M. A. (2009). Women's satisfaction with delivery care in Nairobi's informalsettlements.International Journal for Quality in Health Care, 21(2), 79- 86.

3. Chawani, F. S. (2009). Patient satisfaction with nursing care: a meta synthesis (Doctoral Dissertation, Faculty of Health Sciences, University of the Witwatersrand).

4. Dzakpasu, S., Soremekun, S., Manu, A., ten Asbroek, G., Tawiah, C., Hurt, L., ...\& Kirkwood, B. R. (2012). Impact of free delivery care on health facility delivery and insurance coverage in Ghana's BrongAhafo region. PLOS ONE 7(11): e49430. doi:10.1371/journal.pone.0049430

5. Kenya National Bureau of Statistics (KNBS) and ICF Macro. (2014). Kenya Demographic and Health Survey. Calverton, Maryland: KNBS and ICF Macro

6. Kenya National Bureau of Statistics (KNBS) and ICF Macro. (2010). Kenya Demographic and Health Survey 2008-09. Calverton, Maryland: KNBS and ICF Macro

7. McPake, B., Witter, S., Ensor, T., Fustukian, S., Newlands, D., Martineau, T., \&Chirwa, Y. (2013). Removing financial barriers to access reproductive, maternal and newborn health services: the challenges and policy implications for human resources for health. HumResour Health, 11(1), 46.

8. Ministry of Health, Health Sector Monitoring \& Evaluation Unit, (2015). Status of program in the devolved health system in kenya. A Comprehensive AssessmentReport. WHO and UKAID

9. Nketiah-Amponsah, E., \&Hiemenz, U. (2009). Determinants of consumer satisfaction of health care in Ghana: does choice of health care provider matter? Global Journal ofHealthScience, 1(2), p50.

10. Nyongesa, M. W., Onyango, R., \&Kakai, R. (2014). Determinants of clients' satisfaction with healthcare services at Pumwani Maternity Hospital in Nairobi-Kenya. International Journal of Social and Behavioral Sciences 2(1), pp. 011-017

11. Schoenfelder, T., Klewer, J., \&Kugler, J. (2011). Determinants of patient satisfaction: a study among 39 hospitals in an in-patient setting in Germany. International journal for quality in health care, 23(5), 503-509. 